\title{
Labelling of biopolymers: current status and future trends
}

\author{
Jörg Bettmer • Uwe Karst
}

Published online: 12 June 2010

(C) Springer-Verlag 2010

Biopolymers such as peptides and proteins, carbohydrates and nucleic acids have always posed major challenges to analytical chemistry. Initially, the limited sensitivity and selectivity of UV/vis absorbance detection after liquid chromatographic or electrophoretic separation triggered the development of strongly absorbing or fluorescent labels for biopolymers. Due to the different functional groups to be derivatized, a large number of chromogenic and fluorogenic reagents have been synthesized and applied to achieve increased selectivity and superior limits of detection. The most well-known example is probably 2,4dinitrofluorobenzene, which was introduced by Sanger for the derivatization of amino groups in peptides or proteins.

The development of electrospray ionization mass spectrometry (ESI-MS) by Fenn and matrix-assisted laser desorption ionization mass spectrometry (MALDI-MS) by Karas and Hillenkamp in the second half of the 1980s suddenly made biopolymers directly accessible by mass spectrometry. Therefore, many of the traditional labelling strategies rapidly lost their importance in peptide/protein and carbohydrate analysis. However, due to the limited number of different nucleobases and the possibility of

\footnotetext{
J. Bettmer $(\bowtie)$

Departamento de Química Física y Analítica,

Universidad de Oviedo,

C/ Julián Clavería 8,

33006 Oviedo, Spain

e-mail: bettmerjorg@uniovi.es

U. Karst $(\bowtie)$

Institut für Anorganische und Analytische Chemie,

Westfälische Wilhelms-Universität Münster,

Corrensstr. 30,

48149 Münster, Germany

e-mail: uk@uni-muenster.de
}

amplifying nucleic acids via the polymerase chain reaction (PCR), fluorogenic labelling reagents retained their major role in DNA and RNA analysis, although they were increasingly combined with rapid and miniaturized separation technologies for sequencing, such as microchip-based capillary electrophoresis. These approaches have already been discussed in many reviews and special issues in various scientific journals, and so are not considered in this issue.

This special issue focusses on selected techniques for the mass spectrometric detection of labelled proteins and carbohydrates. Two major areas are covered: novel identification techniques for carbohydrates, proteins and their conjugates, and innovative approaches for protein quantification. Established stable isotope-based techniques for differential proteomics, such as ICAT, ITRAQ and SILAC, have been discussed exhaustively elsewhere and are therefore not covered in this special issue. Five reviews included here present various important topics: crosslinking techniques for studying protein-protein interactions; approaches to oxidative protein labelling; dedicated labelling techniques for glycans; organometallic derivatizing agents for use in bioanalysis; and isotope dilution ICP-MS techniques applied in protein analysis. Three original papers provided here focus on special topics, such as the labelling of peptides and proteins with ferrocene-based reagents, the quantification of the enzyme SOD with species-specific isotope dilution, and a study of the interaction of the bactericide Mercurochrome ${ }^{\circledR}$ with proteins.

Our sincerest thanks to the authors of these manuscripts for their great efforts in contributing to this collection of publications on innovative approaches to biopolymer labelling. We hope that these papers will provide much inspiration to those reading through this special issue! 


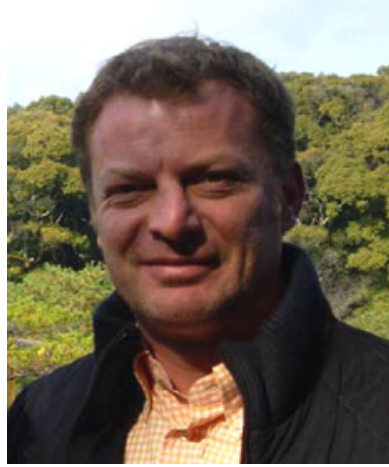

Jörg Bettmer

received his $\mathrm{Ph} . \mathrm{D}$. at the University of Münster, Germany (under the supervision of Professor Karl Cammann) and his habilitation in analytical chemistry at the University of Mainz, Germany (Professor Klaus G. Heumann). Since the summer of 2007 he has been working as a Ramón y Cajal researcher at the University of Oviedo, Spain (Professor Alfredo Sanz-Medel). His research interests are focussed on the development and application of MS-based hyphenated techniques in the fields of elemental speciation, metallomics, and quantitative proteomics and genomics.

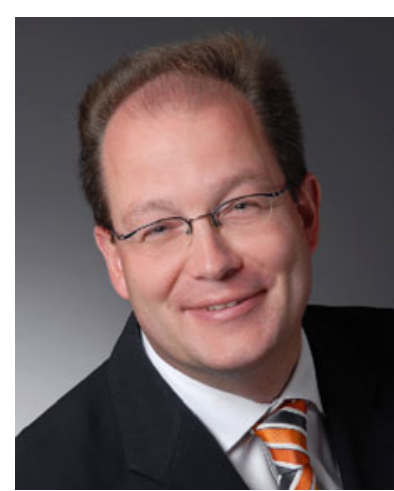

Uwe Karst

received his Ph.D. at the University of Münster, Germany in the group of Karl Cammann, and then moved to the University of Colorado in Boulder for a postdoctoral fellowship with Robert E. Sievers. After finishing his habilitation in Münster, he was appointed a Full Professor of Chemical Analysis at the University of Twente, The Netherlands. In 2005, he assumed his current position as Chair of Analytical Chemistry in Münster. His main research interests include hyphenated techniques, in particular focussing on pharmaceutical analysis, elemental speciation and metallomics. 